\title{
Reconstructive surgery versus nephrectomy in renal artery stenosis: comparison of effects on total and divided renal function and on blood pressure
}

\author{
A MACKAY, J J BROWN, A F LEVER, J I S ROBERTSON
}

\section{Summary and conclusions}

Twenty-six hypertensive patients with unilateral renal artery disease and normal overall renal function were treated surgically: eleven underwent arterial reconstruction and 15 unilateral nephrectomy. One year after operation there was similar reduction in blood pressure in each group ( $\Delta$ mean BP $45.3 \mathrm{~mm} \mathrm{Hg}(p<0.001)$ and 36.8 $\mathrm{mm} \cdot \mathrm{Hg}(\mathbf{p}<0.001)$ respectively). Contrary to previous reports, however, a small but significant improvement in overall renal function was observed in patients who under went reconstructive surgery ( $\Delta$ mean serum creatinine $-13.3 \mu \mathrm{mol} / 1(p<0.01))$; this was associated with a significant rise in para-aminohippurate (PAH) clearance in the operated kidney, while PAH clearance fell on the contralateral side. Overall renal function deteriorated in the patients who underwent unilateral nephrectomy ( $\Delta$ mean serum creatinine $+22.7 \mu \mathrm{mol} / 1(p<0.01))$. The latter was due partly to diminished clearance in the remaining kidney and partly to the loss of the excised kidney.

The findings emphasise the superiority of renal artery reconstruction over nephrectomy in patients with renovascular hypertension.

\section{Introduction}

One of the aims of surgical treatment in hypertensive patients with renal artery stenosis is to lower blood pressure ${ }^{12}$; both nephrectomy and renal artery reconstruction are successful in a proportion of such patients.

Occasionally, however, the primary purpose of renal arterial reconstruction is to enhance renal function. Such improvement has been reported in patients with overall renal impairment both with bilateral renal artery stenosis ${ }^{3}{ }^{4}$ and with stenosis of the artery to a solitary kidney. ${ }^{5}{ }^{6}$ Most patients with renovascular hypertension referred for surgery however, have normal or only mildly impaired renal function. In these, renal arterial reconstruction results either in no change, ${ }^{7}$ or occasionally even mild deterioration, ${ }^{6}$ in renal function.

Such findings are surprising, because the kidney distal to renal artery stenosis should have potentially excellent function, being protected from the adverse effects of hypertension, whereas the contralateral kidney may have suffered vascular damage. ${ }^{1}$ Because our own experience does not accord with these accounts, ${ }^{6} 7$ our findings have been assessed and are reported here.

\footnotetext{
Medical Research Council, Blood Pressure Unit, Western Infirmary, Glasgow G11 6NT

A MACKAY, MB, MRCP, clinical scientist

J J BROWN, MB, FRCP, consultant physician

A F LEVER, MB, FRCP, consultant physician

J I S ROBERTSON, MB, FRCP, consultant physician
}

\section{Patients and methods}

We studied 26 hypertensive patients with unilateral renal artery stenosis or occlusion. All had supine diastolic blood pressures (Vth phase) over $100 \mathrm{~mm} \mathrm{Hg}$ when first seen in the outpatient department. There were 14 men with a mean age of 46 years (range 16-62) and 12 women with a mean age of 44 (range 19-55). Arteriography showed the appearances of occlusion in nine, atheromatous stenosis in fifteen, and fibromuscular hyperplasia ${ }^{8}$ in two. Bilateral ureteric catheterisation studies ${ }^{1}$ confirmed unilateral ischaemia and permitted separate measurement of clearances of para-aminohippurate and endogenous creatinine from each kidney. In addition total creatinine clearance was estimated on two occasions in each patient in 24-hour urine collections. These preoperative assessments were performed while subjects were receiving no treatment (18 patients) or bethanidine only (eight); in all instances any diuretics had been withdrawn at least four weeks previously.

Subsequently all patients came to surgery: 11 (nine with stenosis and two with occlusion) underwent renal artery reconstruction and 15 (eight with stenosis, seven with occlusion) had a unilateral nephrectomy. After a minimum follow-up of one year (mean 19 months) blood pressure, serum urea and serum creatinine concentrations, and 24 -hour creatinine clearance were reassessed. At this point 23 patients were receiving no treatment; two postnephrectomy and one postreconstruction patient were taking beta-blockers; no patient was receiving diuretics. Bilateral ureteric catheterisation studies, with measurements of para-aminohippurate clearance, were repeated in two patients. In 15 cases after operation plasma flow to each kidney was measured using ${ }^{123}$ I-hippuran and a gamma-camera technique, ${ }^{9}$ and was compared with preoperative divided para-aminohippurate clearances. The hippuran clearance measurement has been shown to correlate well with para-aminohippurate clearance ${ }^{9}$; since mean hippuran clearance was shown to equal $97 \%$ of mean para-aminohippurate clearance, no distinction has been drawn between the results of the two techniques in the present study.

Preoperative and postoperative data were compared using the Wilcoxon matched-pairs signed-rank one-tailed test. ${ }^{10}$ Mean blood pressure was taken as the Vth phase diastolic value plus one-third of the pulse pressure.

\section{Results}

Both reconstructive surgery and nephrectomy led to significant reductions in mean values for systolic, diastolic, and mean blood pressure at one year $(p<0.001$ for each-see figure). The response was slightly, but insignificantly, greater after arterial reconstruction $(\Delta$ mean BP $45.3 \mathrm{~mm} \mathrm{Hg}$ ) than after nephrectomy ( $\Delta$ mean BP 36.8 $\mathrm{mm} \mathrm{Hg})$.

Preoperative serum urea (mean $5.4 \mathrm{mmol} / \mathrm{l}$, range $3 \cdot 4-10 \cdot 1 \mathrm{mmol} / \mathrm{l}$ ) and creatinine (mean $102 \mu \mathrm{mol} / \mathrm{l}$, range 55-146 $\mu \mathrm{mol} / \mathrm{l}$ ) concentrations were within, or just above, the respective normal ranges, and the mean preoperative values were not different in the groups having nephrectomy or arterial reconstruction. Clearances of creatinine and para-aminohippurate were slightly $(15 \%$ and $11 \%$ respectively), but not significantly, lower in the patients coming to nephrectomy (see figure).

Postoperatively, patients who underwent nephrectomy experienced a $35 \%$ increase in serum urea concentration $(p<0.005)$, a $23 \%$ increase in serum creatinine concentration $(p>0.005)$, a $24 \%$ decrease in creatinine clearance $(p<0.005)$, and a $21 \%$ decrease in total paraaminohippurate clearance $(\mathrm{p}<0.005)$. The lowest creatinine clearance postoperatively was $24 \mathrm{ml} / \mathrm{min}$, and no patient subsequently required dialysis. By contrast, after reconstructive surgery, there was a $13 \%$ increase in creatinine clearance $(p=0.025)$, a $9 \%$ increase in tota 
para-aminohippurate clearance (NS), an $8 \%$ decrease in serum urea concentration (NS), and a $14 \%$ decrease in serum creatinine concentration $(p<0 \cdot 005)$.

After renal artery reconstruction, effective renal plasma flow rose on the operated side by $25 \%$ from a mean of 156 to $195 \mathrm{ml} / \mathrm{min}$ $(p=0.025)$. On the unoperated side, however, there was a postoperative fall of $13 \%$, from 316 to $275 \mathrm{ml} / \mathrm{min}$ (NS); thus net paraaminohippurate clearance rose by only $9 \%$. Similarly, in patients who had unilateral nephrectomy renal plasma flow fell by $5 \%$ (NS) from 285 to $270 \mathrm{ml} / \mathrm{min}$ in the contralateral kidney.

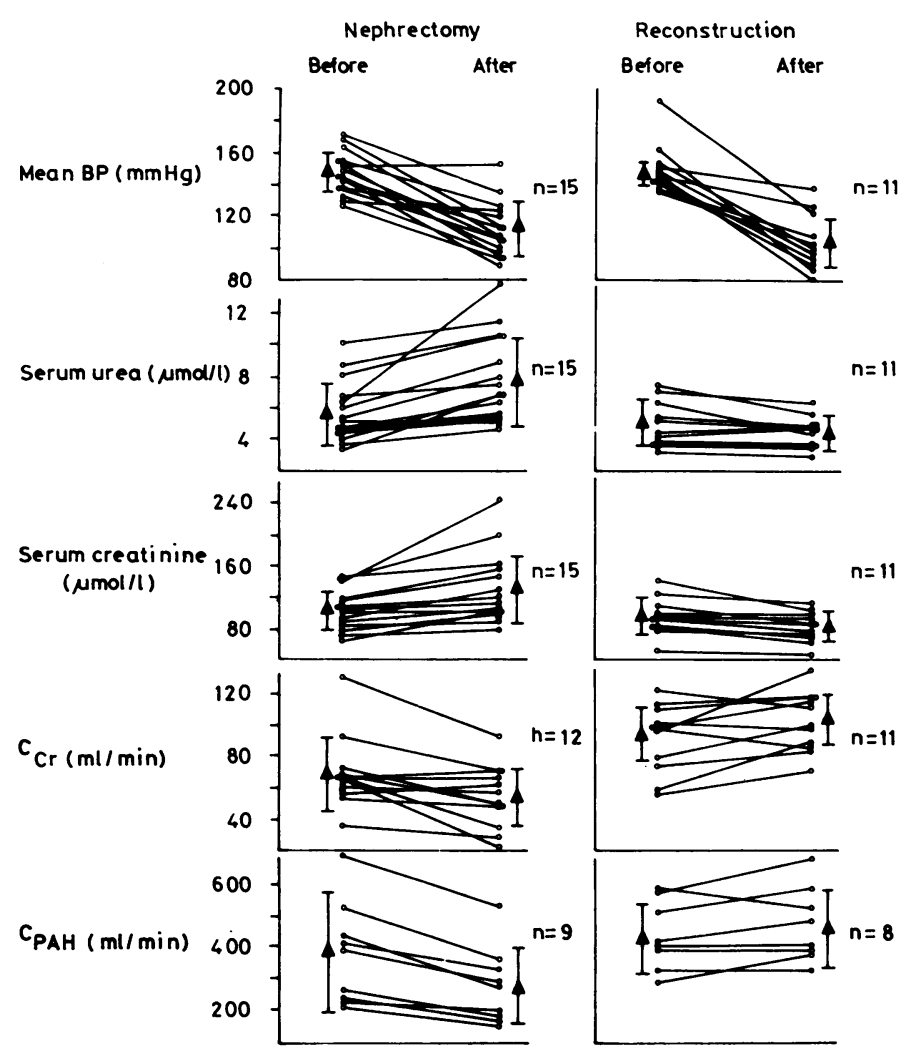

Consequences of surgery in renal artery stenosis-changes in (a) mean arterial pressure ( $\mathrm{mm} \mathrm{Hg}$ ), (b) serum urea concentration (mmol/1), (c) serum creatinine concentration $(\mu \mathrm{mol} / \mathrm{l})$, (d) creatinine clearance $(\mathrm{ml} / \mathrm{min})$, and (e) para-aminohippurate clearance $(\mathrm{ml} / \mathrm{min})$. Closed triangles with bars represent mean \pm 1 standard deviation.

\section{Discussion}

In this series the primary object of surgery was to lower raised blood pressure, and this was achieved to a comparable extent in both surgically treated groups (figure). While nephrectomy produced a deterioration in renal function, however, arterial reconstruction resulted in improvement, albeit with values that were within the overall normal range for most patients both before and one year after surgery.

Kaufman ${ }^{6}$ described similar results after unilateral nephrectomy in patients having normal preoperative renal function, with a $19 \%$ reduction in creatinine clearance postoperatively. In contrast to our experience, however, he found a small (5\%) deterioration in mean creatinine clearance after reconstructive surgery also, though this was not statistically significant. Simon and del $\mathrm{Greco}^{7}$ similarly failed to find any overall increase in function after arterial reconstruction in patients in whom preoperative renal function was normal.

This issue becomes crucial when considering operation in patients with initial renal impairment. Several reports describe considerable improvement after reconstructive surgery in such patients.4 7 11-13 Recently, we ${ }^{14}$ have observed one severely hypertensive woman who 17 months after unilateral nephrectomy for renal artery occlusion suffered thrombosis of her remaining renal artery. Anuria followed with serum creatinine concentration rising to $1258 \mu \mathrm{mol} / 1$. Emergency reconstructive surgery was successful in returning renal function to near normal and in moderating hypertension. Other evidence suggests that function may be recovered after restoring the blood supply to a chronically anuric kidney with an occluded renal artery ${ }^{15}$; in such cases a collateral circulation has provided sufficient blood only to maintain viability of the renal parenchyma. ${ }^{16}$

We observed in the present study that the $25 \%$ increase in effective renal plasma flow through the reconstructed renal artery was accompanied by a $13 \%$ fall in plasma flow to the contralateral kidney; thus overall only a $9 \%$ increase was recorded. Simon and del $\mathrm{Greco}^{7}$ have noted this differential effect, and $\mathrm{O}^{\prime}$ Conor $^{17}$ also has described a contralateral decrease in both creatinine clearance and filtration fraction in patients whose stenosed renal artery was successfully reconstructed. By contrast, it has also been shown ${ }^{7}$ that where reconstruction failed to lower blood pressure, considerable disparity between the function of the two kidneys remained. This may have been due to continuing ischaemia on the affected side or to irreversible hypertensive damage in the contralateral kidney. We have also shown that a small decrease in plasma flow to the contralateral kidney occurred after unilateral nephrectomy. The reduction in mean blood pressure was similar in both operated groups, and the findings therefore suggest that the contralateral kidney, suffering variable intrarenal hypertensive vascular changes, is partly dependent on a high perfusion pressure to sustain its function. This, together with the loss of the excised kidney, could account for the reduction in overall function after nephrectomy.

The present study has shown the superiority of reconstructive surgery over unilateral nephrectomy in the surgical management of hypertensive patients with renal artery stenosis, particularly in preserving renal function. Furthermore, nephrectomy limits future surgical options should contralateral disease develop. The recent introduction of percutaneous transluminal angioplasty ${ }^{1819}$ offers a further means of arterial reconstruction: although a controlled trial comparing this relatively noninvasive technique with conventional reconstructive surgery has not been published, current evidence suggests that angioplasty may be as effective in lowering blood pressure as conventional surgery, but free from the hazards of major abdominal surgery. Renal artery reconstruction (or perhaps dilatation) should therefore be preferred to nephrectomy in all patients with renal artery stenosis coming to operation.

Operations were performed by Mr H Forrest, Mr A G Graham, and the late Mr J Kennedy Watt.

\section{References}

1 Brown JJ, Owen K, Peart WS, Robertson JIS, Sutton D. The diagnosis and treatment of renal artery stenosis. Br Med F 1960:ii:327-38.

${ }^{2}$ Foster JH, Maxwell MH, Franklin SS, et al. Renovascular occlusive disease : results of operative treatment. $\mathcal{F} A M A$ 1975;231:1043-8.

3 Morris GC, de Bakey MF, Cooley DA, Crawford ES. Experience with 200 renal artery reconstructive procedures for hypertension or renal failure. Circulation 1963;27:346-50.

4 Bengtsson U, Bergentz SE, Norback B. Surgical treatment of renal artery stenosis with impending uraemia. Clin Nephrol $1974 ; 2: 222-9$.

5 Baird RJ, Yendt ER, Firor WB. Anuria due to acute occlusion of the artery to a solitary kidney. Successful treatment by operative means. $N$ Engl f Med $1965 ; 272: 1012-4$.

${ }^{6}$ Kaufman JJ. Renal artery stenosis and azotaemia: does correction of renovascular hypertension improve renal function? Trans Am Assoc Genitourin Surg 1973;65:12-6.

7 Simon NM, del Greco F. Kidney function after renal revascularisation for hypertension. Circulation $1964 ; 29: 376-92$.

8 Youngberg SP, Sheps SC, Strong CG. Fibromuscular disease of the renal arteries. Med Clin North Am 1977;61:623-41.

- Mackay A, Eadie AS, Cumming AMM, Graham AG, Adams FG, Horton PW. Assessment of total and divided renal plasma flow by ${ }^{123}$ I-hippuran renography. Kidney Int (in press).

10 Siegel S. Non-parametric statistics for the behavioural sciences. Tokyo: McGraw Hill, 1956. 
11 Smith HT, Shapiro FL, Messner RP. Anuria secondary to renovascular disease. F $A M A$ 1968;204:928-30.

12 Sheil AGR, May J, Stokes GS, Johnson JR, Tiller DJ, Stewart JH. Reversal of renal failure by revascularisation of kidneys with thrombosed renal arteries. Lancet 1973 ;ii:865-6.

${ }^{13}$ Morgan T, Wilson M, Johnston W, Clunie GJ, Gordon R. Restoration of renal function by arterial surgery. Lancet $1974 ; \mathrm{i}: 653-6$.

${ }^{14}$ Mackay A. Recovery of renal function after renovascular surgery. Scott Med F (in press).

${ }^{15}$ Perkins RP, Jacobsen DS, Feder FP, Lipchik EO, Fine PH. Return of renal function after late embolectomy. $N$ Engl f Med 1967;276:1194-5.
${ }^{16}$ Morris GCJ, Heider C, Moyer JH. The protective effect of subfiltration arterial pressure on the kidney. Surg Forum 1955;6:623-7.

17 O'Conor VJ. Renal artery stenosis and azotaemia. Trans Am Assoc Genitourin Surg 1973;65:17.

18 Grüntzig A, Kuhlmann U, Vetter W, Lütolf V, Meier B, Siegenthaler W. Treatment of renovascular hypertension with percutaneous transluminal dilatation of a renal artery stenosis. Lancet $1978 ; \mathrm{i}: 801-2$.

19 Katzen BT, Chang J, Lukowsky GH, Abramson EG. Percutaneous transluminal angioplasty for treatment of renovascular hypertension. Radiology 1979;131:53-8.

\title{
Generalised tissue abnormality of aryl hydrocarbon hydroxylase in psoriasis
}

\author{
P H CHAPMAN，P J KERSEY， BARBARA KEYS， SAM SHUSTER，M D RAWLINS
}

\section{Summary and conclusions}

Microsomal aryl hydrocarbon hydroxylase (AHH) activity and inducibility were measured in jejunal mucosa, liver, and lesion-free epidermis of patients with psoriasis. In all three tissues AHH activity and inducibility were less than in controls.

This demonstration of a generalised enzymatic abnormality in the tissues of patients with psoriasis is in keeping with the suggestion that it may be close to the underlying genetic defect.

\section{Introduction}

We have recently reported that the activity of epidermal aryl hydrocarbon hydroxylase ( $\mathrm{AHH}, \mathrm{EC} 1.1414 .2)$ is reduced in the untreated, clinically normal, lesion-free skin of patients with chronic discoid ${ }^{1}$ and palmar-plantar pustular psoriasis. ${ }^{2}$ Moreover, in-vitro induction of $\mathrm{AHH}$ by incubation with benzanthracene was less than in skin from people without psoriasis. Because this abnormality appears to be unique to psoriasis $^{3}$ and because it affects skin which has never been affected by the lesions of psoriasis ${ }^{2}$ we have suggested that it may be related to the underlying genetic defect of the disease. ${ }^{2}{ }^{4}$ If this suggestion is correct it might be expected that a similar defect would also occur in tissues other than skin. We therefore measured microsomal AHH activity in the jejunal mucosa and liver of patients with psoriasis.

\section{Patients and methods}

Epidermal biopsy-Epidermal biopsy specimens were obtained by suction blisters from 43 patients (aged 18-73) with chronic psoriasis. Four of these also underwent liver or jejunal biopsy, or both. There were 73 biopsy specimens from control subjects of comparable age but without psoriasis.

\footnotetext{
Department of Dermatology, Newcastle University, Newcastle upon Tyne NE1 4LP

P J KERSEY, MRCP, senior registrar

SAM SHUSTER, PHD, FRCP, professor

Department of Clinical Pharmacology, Wolfson Unit, Newcastle University, Newcastle upon Tyne NE1 7RU

P H CHAPMAN, PHD, Janssen lecturer

BARBARA KEYS, research technician

M D RAWLINS, MD, FRCP, professor
}

fejunal biopsy-Eight patients (four men) with chronic discoid psoriasis (aged 19-58 years) affecting $10-30 \%$ of their body surface and 11 patients (five men; aged $46 \pm$ SE 5 years) with disorders unassociated with abnormal epidermal $\mathrm{AHH}$ activity (eczema, 4 patients; parapsoriasis, 1 ; geographic tongue, 1 ; polyarthropathy, 1 ; Gorlin's syndrome, 1 ; erythema elevatum diutinum, 1 ; normal, 2) underwent jejunal biopsy with a modified Crosby capsule under fluoroscopic control. No patient had received any systemic or topical drug treatment during the three weeks before biopsy. Fully informed consent was obtained from all patients undergoing jejunal and epidermal biopsies.

Hepatic biopsy-Liver tissue was obtained from 13 patients undergoing percutaneous (Menghini needle) biopsy for diagnostic purposes, when it was surplus to that required for histology. Six patients (all men; aged 41-71 years) had chronic discoid psoriasis and were undergoing assessment for methotrexate treatment; five patients (all men; aged 27-72 years) with parapsoriasis and mycosis fungoides were undergoing investigation for systemic reticulosis. None of these patients had clinical or biochemical evidence of liver disease (serum bilirubin, aspartate transaminase, alkaline phosphatase, albumin), none were taking drugs at the time of study, and all had normal liver histological findings. In addition liver was studied from two patients in whom cirrhosis was suspected: in one the liver was found to be normal and the other had minimal cirrhosis.

Measurement of AHH activity-Biopsy samples were immediately placed in ice-cold TRIS buffer ( $\mathrm{pH} 7 \cdot 4)$ and transferred to the laboratory, where the specimen was divided into two parts and weighed. Both portions were incubated in a tissue culture system for 18 hours at $37^{\circ} \mathrm{C}$ in an atmosphere of $95 \% \mathrm{O}_{2}: 5 \% \mathrm{CO}_{2}{ }^{5}$; one portion was incubated in medium containing benzanthracene $(100 \mu \mathrm{g} / \mathrm{mol} / \mathrm{l})$. Microsomal AHH activity was measured using benz(a)pyrene as substrate, and expressed as pmol 3-hydroxybenzpyrene formed/mg microsomal protein/hour (pmol 3-OH BP/mg protein/h). "Basal" and "induced" AHH activities were calculated from results obtained after incubation without and with benzanthracene. The induction ratio was calculated from the ratio of induced to basal AHH activities. ${ }^{1}$

\section{Results}

The results (see table) were the same for all three tissues and showed that basal AHH activity in psoriatics was significantly less than in the controls. After induction by preincubation with benzanthracene, AHH activity was similarly less in psoriatics than in the controls; thus, the induction ratio was less than normal in all three tissues from psoriatic patients.

\section{Discussion}

These results confirm our previous observations ${ }^{12}$ that $\mathrm{AHH}$ activity and inducibility is reduced in the clinically normal skin 